\title{
Characterization of Zeolite-supported Pt Catalysts by Image Analysis
}

\author{
J. O. Huertas Flores, J. R. J. Zumarán Farfán, M. I. Pais da Silva, P. M. Jardim and S. Paciornik
}

Chemistry Department, Materials Science and Metallurgy Department, PUC-Rio, Rua Marquês de São Vicente, 225 - Gávea - 22453-900, Rio de Janeiro, RJ, Brazil.

Zeolite-supported metallic catalysts are very important in the chemistry industry, especially in naphtha related reactions such as dehydrogenation of naphthenics to aromatics and paraffin hidroisomerisation. In the $\mathrm{Pt} / \mathrm{KL}$-zeolite catalyst the size and dispersion of the metallic particles are fundamental parameters for its performance [1,2]. Different methods of metal introduction are employed to achieve the desired properties. In the present work, samples prepared by ionic exchange (IE) and wet point impregnation (WPI) were analyzed.

The metallic particles are nm-sized and thus TEM is required for their characterization [2]. However, as shown in Figure 1, it is not an easy task to discriminate the particles in a TEM image, due to the strong changes in contrast that result from the varying thickness of the zeolite support.

A procedure for quantitative microscopy of the Pt particles was developed. It follows the classical sequence of Image Processing and Analysis: image acquisition, pre-processing, segmentation, postprocessing and measurement. As complete discrimination of the particles was deemed impossible, the rationale behind the procedure was to detect as many correctly shaped particles as possible, while eliminating spurious objects based on various size and shape criteria. This logic, even if reducing the statistics of detected particles, guaranteed that the measured objects effectively corresponded to single Pt particles.

TEM images at $200 \mathrm{kX}$ were acquired on film and directly digitized with a slide scanner at 0.18 $\mathrm{nm} /$ pixel. A median filter was used to reduce high-frequency noise [3]. A first order discrimination of the particles was achieved with and adaptive segmentation method that applies a local background subtraction to regions of the image (Fig. 1 top-right) [3]. The detected objects belonged to four classes: individual $\mathrm{Pt}$ particles, groups of touching $\mathrm{Pt}$ particles, irregular shaped regions, and spurious objects detected outside of the zeolite support. Very large and very small objects were excluded based on a size threshold. Touching particles were separated using the watershed algorithm, and resulting objects were selected based on circularity [4] (Fig. 2 bottom-right). The result shows the outlines of the detected particles superimposed on the original image. It can be seen that a large percentage of the particles was detected and no spurious objects were included in the database.

Measurements of area, equivalent circular diameter and mean chord size were then obtained, for several fields, for both kinds of samples (Figure 2). The results are consistent with the literature that states that the IE preparation method favors smaller particles because they can go into sites were ionic exchange between $\mathrm{Pt}^{+2}$ and the zeolite $\mathrm{Na}^{+}$or $\mathrm{K}^{+}$ions can occur. On the other hand, the WPI method does not allow such a good dispersion of the metal at molecular level, leading to larger particles $[5,6]$. The developed procedure seems to be quite generic and can be applied to similar images, with simple adjustments of the segmentation and post-processing parameters. 


\section{References}

[1] S. V. C. Magno. M. Sc. Dissertation, Chemistry Dept. PUC-Rio, 1999 (in Portuguese).

[2] M. I. Pais, D. Bartholeuf, CIT Información tecnológica vol. 10 N 6, 1999.

[3] J. C. Russ, Computer Assisted Microscopy, Plenum Press, New York, 1990.

[4] S. Paciornik et al, Comp. Sci. Tec. 63 (2003), 295.

[5] C. M. Valadares, Proceedings XVII Ibero-American Symposium on Catalysis, Portugal, 2000.

[6] B. C. Gates, Catalytic Chemistry, John Wiley \& Sons, New York, 1992.
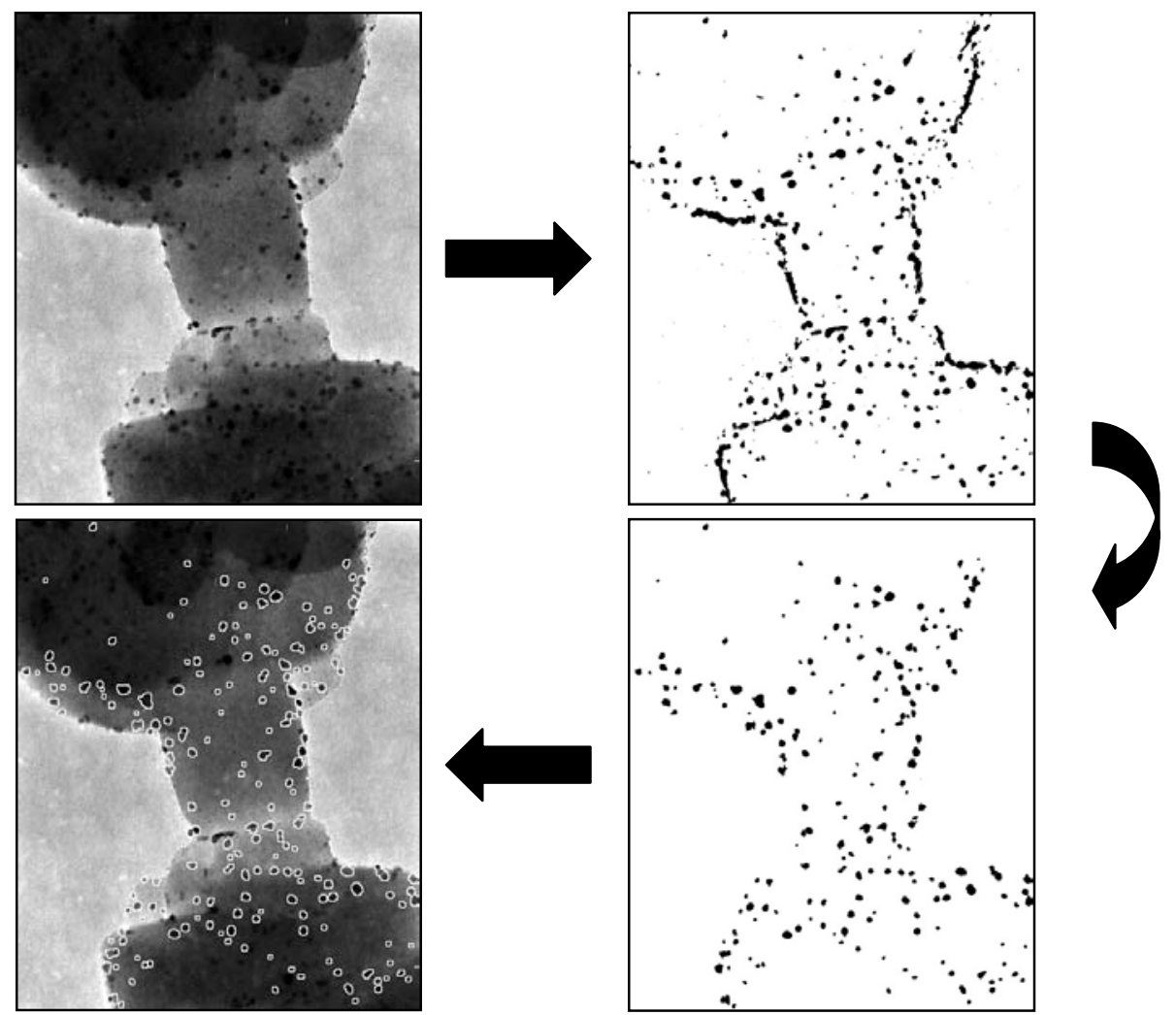

Figure 1 - Image processing sequence. Original image. After adaptive segmentation. After postprocessing. Detected particles superimposed on original image.
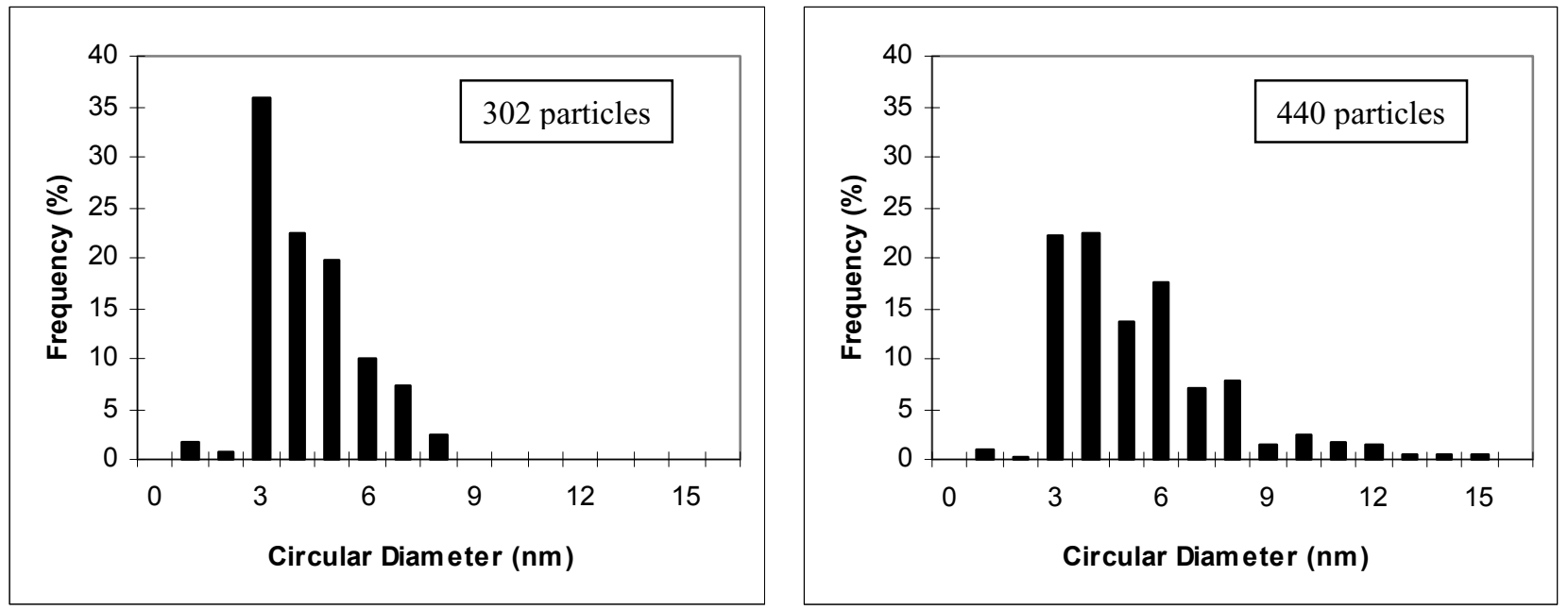

Figure 2 - Equivalent circular diameter distribution for particles in several fields of two distinct samples. Left: Ionic exchange. Right: Wet point impregnation. 